\title{
Orthodromic Atrioventricular Tachycardia in Wolff-Parkinson-White Syndrome with Two Accessory Pathways Participation during the Same AVT
}

Thiago Sampaio Marengo1, Vitor Martins', Guilherme Viana Barbosa², Fernando Mello Porto $^{2,3}$, Halim Cury Filho², Adão Bento de Lucena Neto ${ }^{2,3}$, José Marco Nogueira Lima ${ }^{2,3}$

\section{ORCID ID}

Marengo TS (10) https://orcid.org/0000-0002-0308-767X

Porto FM (10) https://orcid.org/0000-0003-1503-4273

Martins V (i) https://orcid.org/0000-0002-8386-5223

Cury Filho H (1) https://orcid.org/0000-0003-0102-4082

Barbosa GV (1) https://orcid.org/0000-0003-2253-0910

Lucena Neto AB (D) https://orcid.org/0000-0001-6946-1217

Lima JMN (D) https://orcid.org/0000-0002-9377-7649

\begin{abstract}
Case report of a 49-year-old patient with Wolff-Parkinson-White syndrome, very symptomatic, with apparent parahisian pathway who, during an electrophysiological study, presented orthodromic atrioventricular tachycardia, featuring two accessory pathways, retrogradely, the parahisian pathway and a hidden left posterolateral pathway, during the same tachycardia, alternating the retrograde pathway of tachycardia without interruption.
\end{abstract}

KEYWORDS: Wolff-Parkinson-White Syndrome; Accessory atrioventricular bundle; Catheter ablation.

\section{INTRODUCTION}

Several authors have described the coexistence of two accessory pathways in patients with Wolff-Parkinson-White Syndrome (WPW), although this association is uncommon ${ }^{1}$. OEarly diagnosis of WPW Syndrome itself is important because the disease is a condition that, in rare cases, can culminate in sudden death ${ }^{2}$. The syndrome pattern derives from the combination of ventricular pre-excitation generated by the accessory pathway with normal electrical conduction by the atrioventricular node. Such accessory pathway originates in the myocardial chamber during early misfolding between atria and ventricles in embryogenesis. As a result, the electrically conductive pathways of the myocardium anticipate the

1. Universidade Anhembi Morumbi - São Paulo (SP), Brazil.

2. Grupo de Arritmia Campinas - Campinas (SP), Brazil.

3. Serviço de Arritmia e Marcapasso, Pontifícia Universidade Católica de Campinas - Campinas (SP), Brazil. *Corresponding author: thiagosmarengo@gmail.com

Received: Aug 13, 2021 | Accepted: Dec 7, 2021 
normal electrical conduction between the atrium and the ventricle, forming the accessory pathway. ${ }^{3,4}$. This pathway usually has non-decremental or undelayed conduction, which is in contrast to the normal properties of the atrioventricular node.

The electrical conduction characteristics of the accessory pathway can vary and depend on factors such as conduction speed, conduction direction and refractory period. These characteristics, together with the location and number of accessory pathways, will determine how the pathway may or may not be involved with the initiation or triggering of an arrhythmia, leading to WPW syndrome ${ }^{5,6}$. The electrocardiographic manifestation of WPW syndrome is essentially based on a short $\mathrm{P}-\mathrm{R}$ interval with an initial swelling of the QRS complex called the delta wave, with clinical expression of palpitations, precordial discomfort and, occasionally, fainting ${ }^{7}$.

According to the 2015 American College of Cardiology (ACC)/American Heart Association (AHA)/Heart Rhythm Society (HRS) guidelines, catheter ablation has become the first-line treatment for symptomatic patients because of its high success rate and its low risk. Diagnosis of WPW Syndrome with involvement of two accessory pathways is challenging because of the unusual pattern observed in the electrophysiological study in such cases.

This case report aimed to describe such a condition rarely found in patients with this syndrome, because the two anomalous pathways, the apparent parahisian and the posteroseptal of the occult mitral annulus, manifest during the same orthodromic atrioventricular tachycardia (AVT), without interruption, varying the retrograde pathway during the same AVT by both pathways intermittently, initially generating diagnostic difficulty in the electrophysiological study.

\section{CASE REPORT}

A 49-year-old male patient with no other pathologies or comorbidities was referred complaining of tachycardic palpitations since adolescence, well tolerated, which recently became more frequent, becoming less tolerated and lasting for more than 30 minutes, with refractoriness to the use of propafenone.

The patient had normal laboratory tests, Doppler echocardiography without alterations, and the electrocardiogram (Fig. 1) showed ventricular pre-excitation with a pattern of the parahisian pathway.

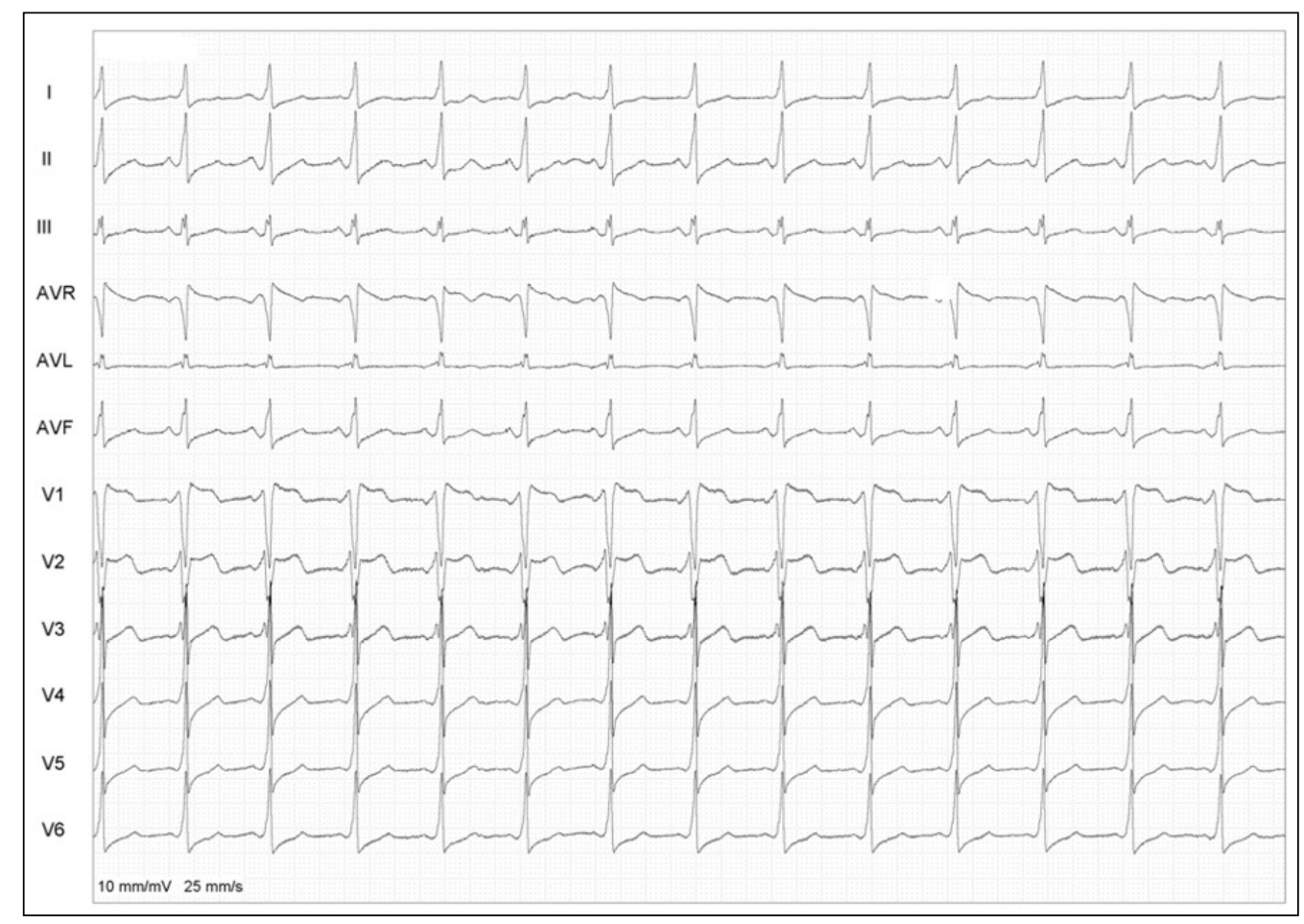

Figure 1. Baseline 12-lead echocardiogram with ventricular pre-excitation. Due to the polarity of the delta wave, a paraHisian location is suggested. 
The invasive electrophysiological study showed the presence of two accessory pathways, an apparent paraHisian (Fig. 2), bidirectional driving (Fig. 3), with an antegrade refractory period of $210 \mathrm{~ms}$, and a hidden left posterolateral period (Fig. 4), with exclusive retrograde conduction.

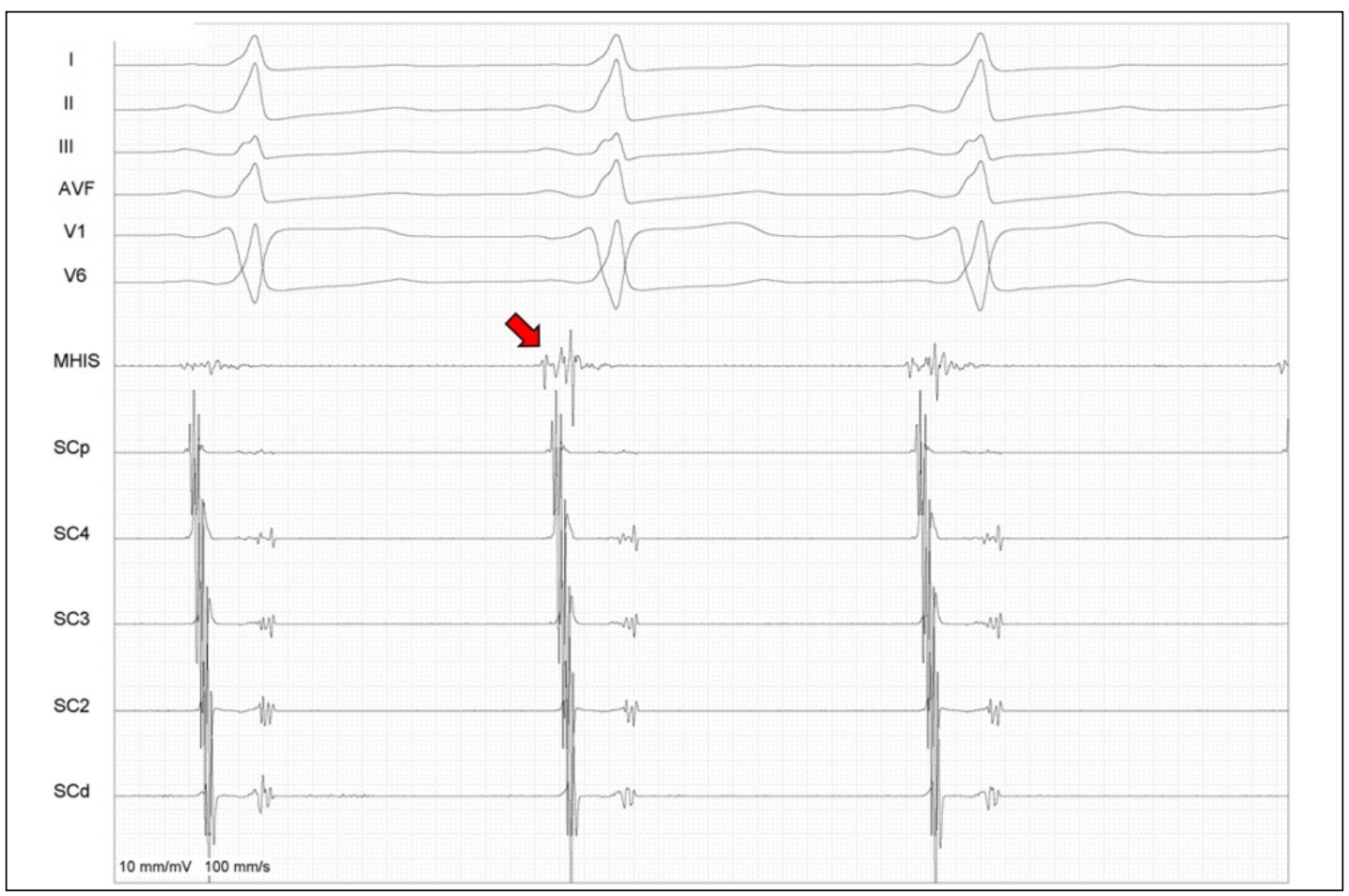

Figure 2. Image of an electrophysiological study with a decapolar catheter located in the coronary sinus ( $\mathrm{SCp}=$ proximal coronary sinus/SCd = distal coronary sinus) and ablator catheter (MHIS) located in the septal region. At the moment, in sinus rhythm. Ablator catheter positioned in the His bundle region, with continuous atrioventricular potential, demonstrating anterograde conduction via an accessory pathway in this region.

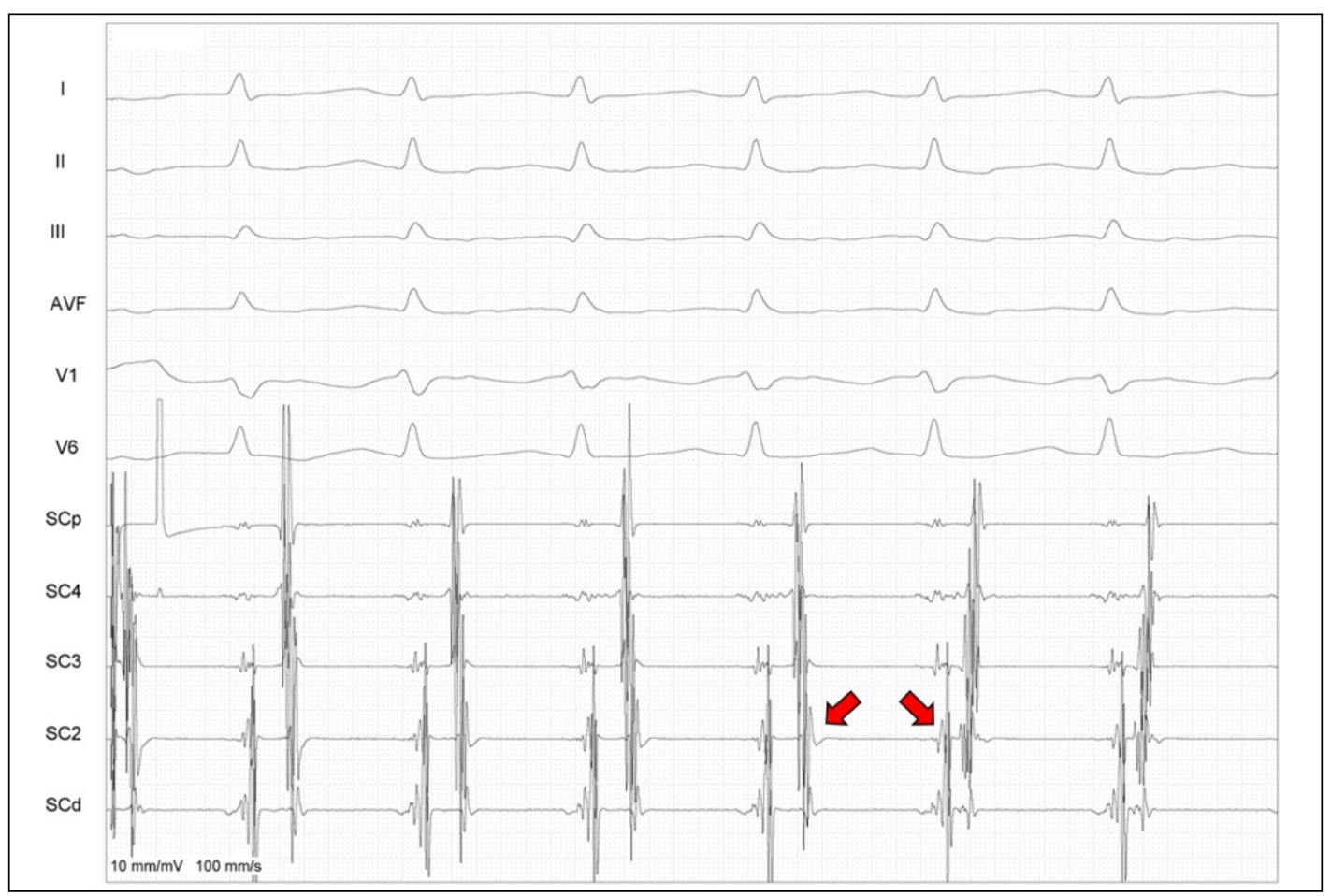

Figure 3. Electrophysiological study during orthodromic atrioventricular tachycardia demonstrating change in the direction of ventricle-atrial activation (retrograde). As shown by the arrow, there is earlier atrial activation in the distal coronary sinus (CSd), region of the lateral wall of the mitral annulus. 


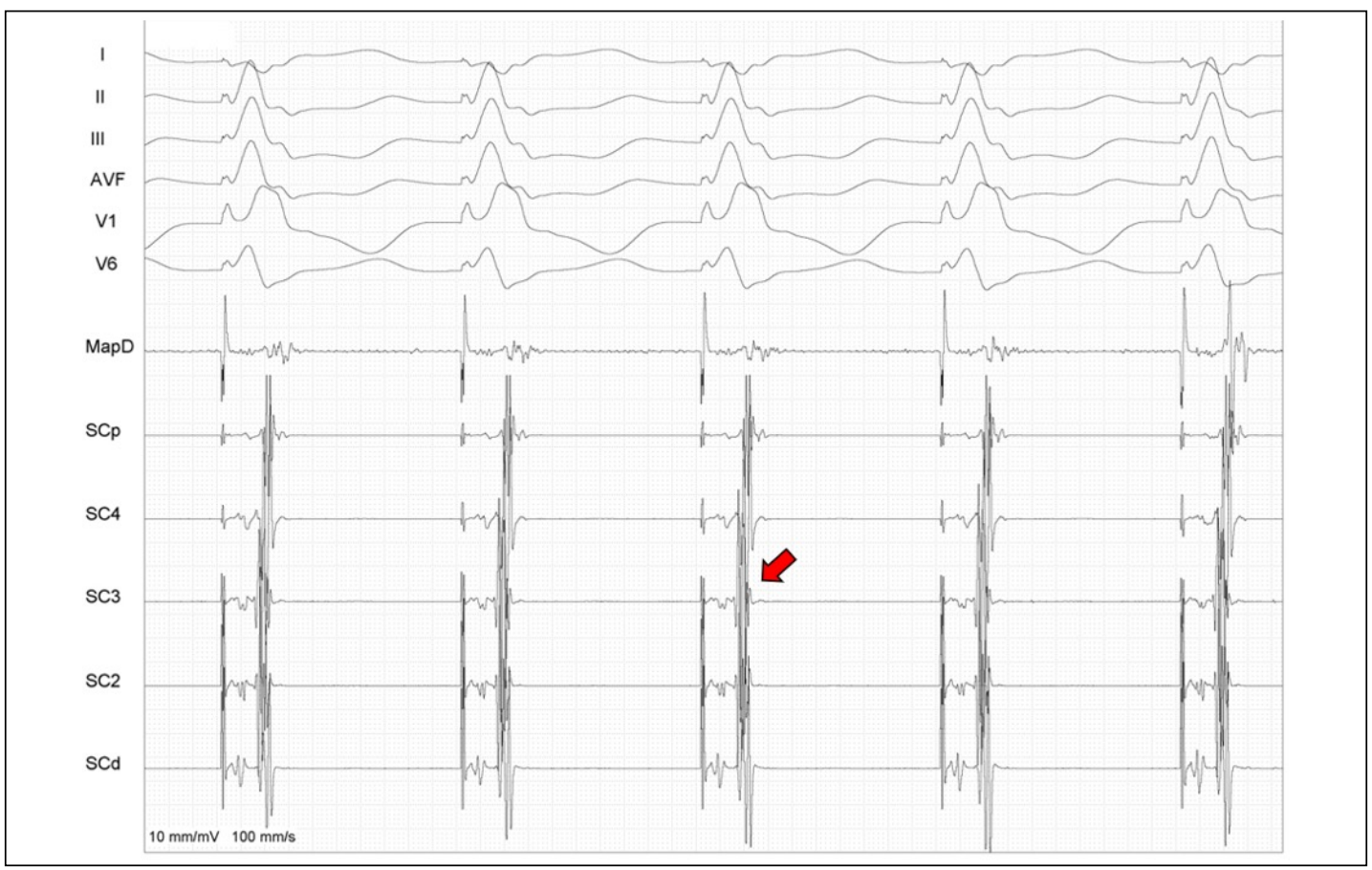

Figure 4. Electrophysiological study image with decapolar catheter located in the coronary sinus (CSp = proximal / CSd = distal) and ablator catheter (MapS) located in the right ventricle. Under programmed pacing of the right ventricle, earlier atrial activation at the distal pole (CSd) was demonstrated, thus confirming retrograde atrial activation via the left lateral route.

Radiofrequency ablation of the two accessory pathways was successfully performed, the first being para-Hisian, using St.Jude material, quadripolar electrode in the right ventricle, decapolar electrode in the coronary venous sinus and $4 \mathrm{~mm}$ ablator, using radiofrequency with a power of $35 \mathrm{Watts}$ and $40^{\circ} \mathrm{C}$, for 60 seconds, to ablate the parahisian route, as cryoablation was not available. The patient had prior consent for the location of the route. Subsequently, the left posterolateral occult pathway was ablated (Fig.5).

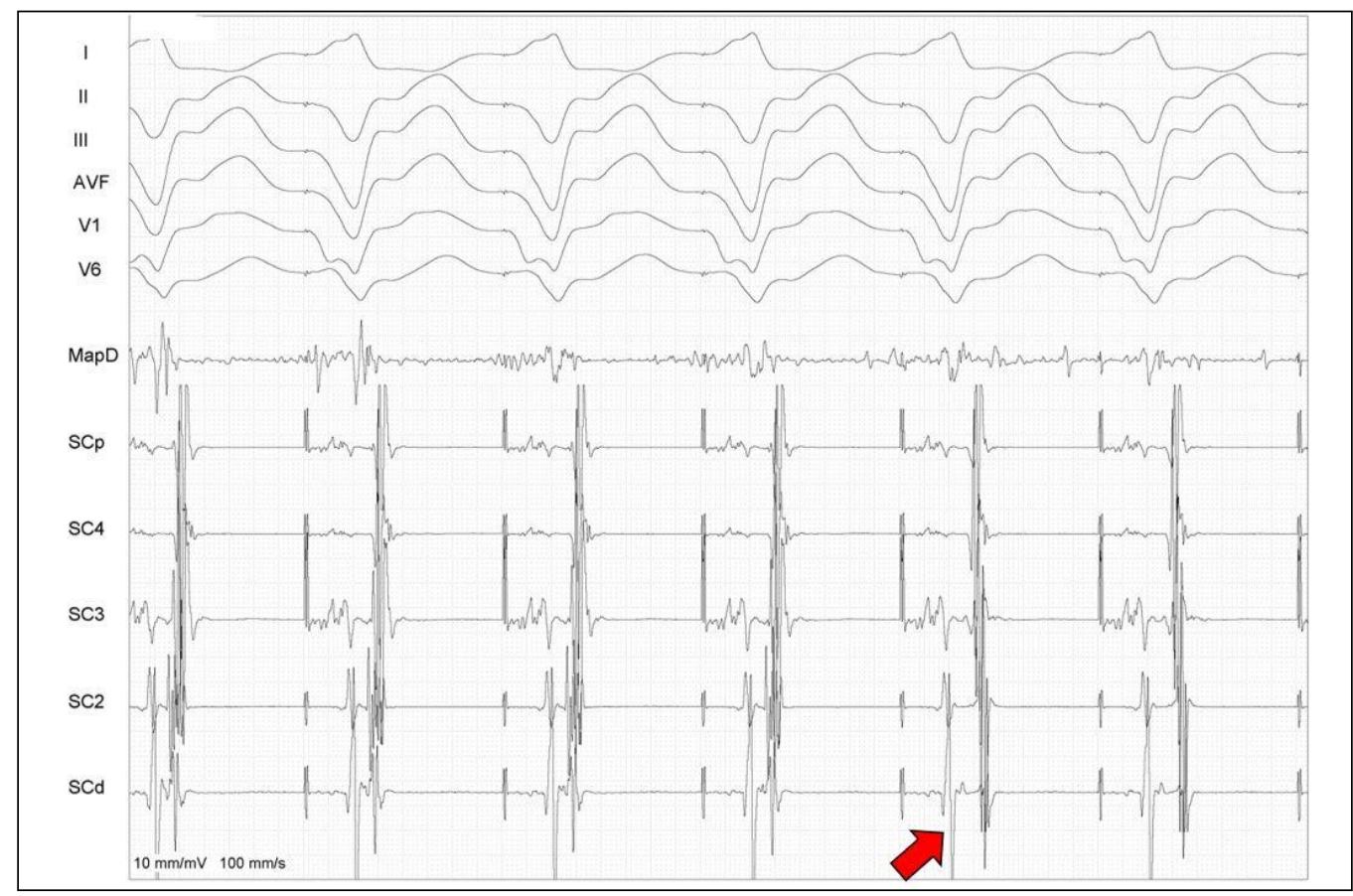

Figure 5. Image of an electrophysiological study during stimulation of the right ventricle showing the opening of the ventriculo-atrial interval after radiofrequency application. Having interrupted conduction through the left posterolateral accessory pathway, as shown by the arrow. Ablation of the left posterolateral occult anomalous pathway performed. 
For mapping the posterior lateral occult pathway of the mitral annulus, a retroaortic technique was used, with the use of radiofrequency with a power of $50 \mathrm{Watts}$ and $60^{\circ} \mathrm{C}$ for 60 seconds, with good parameters for mapping and success. After ablation of both accessory pathways, we could no longer locate them in the electrophysiological study (Fig. 6), while the basal electrocardiogram was classified as normal (Fig. 7).

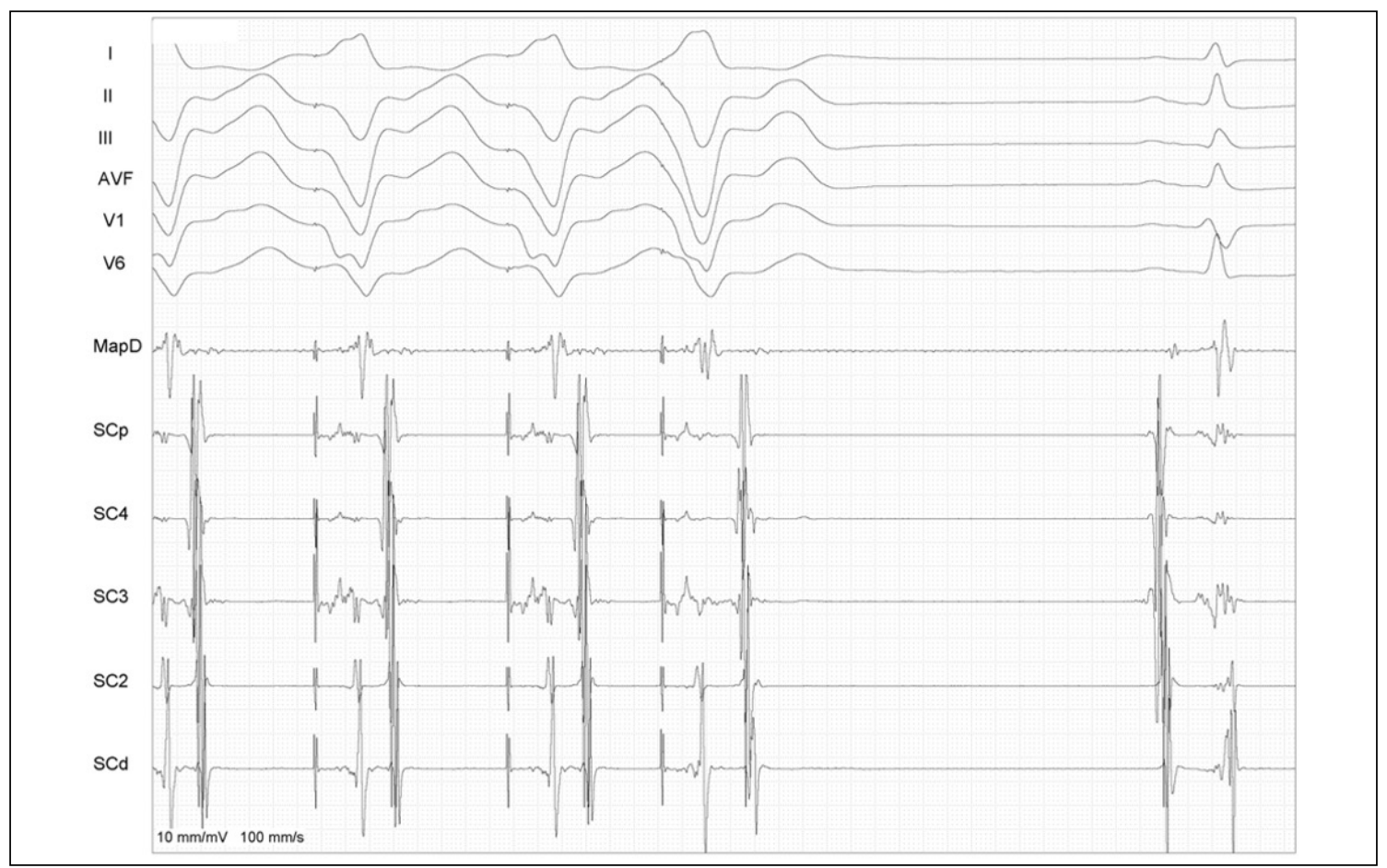

Figure 6. Confirmation of the absence of the bidirectional conduction Hissian pathway and of the left posteroseptal occult anomalous pathway (conduction of the accessory pathway through the atrioventricular node).

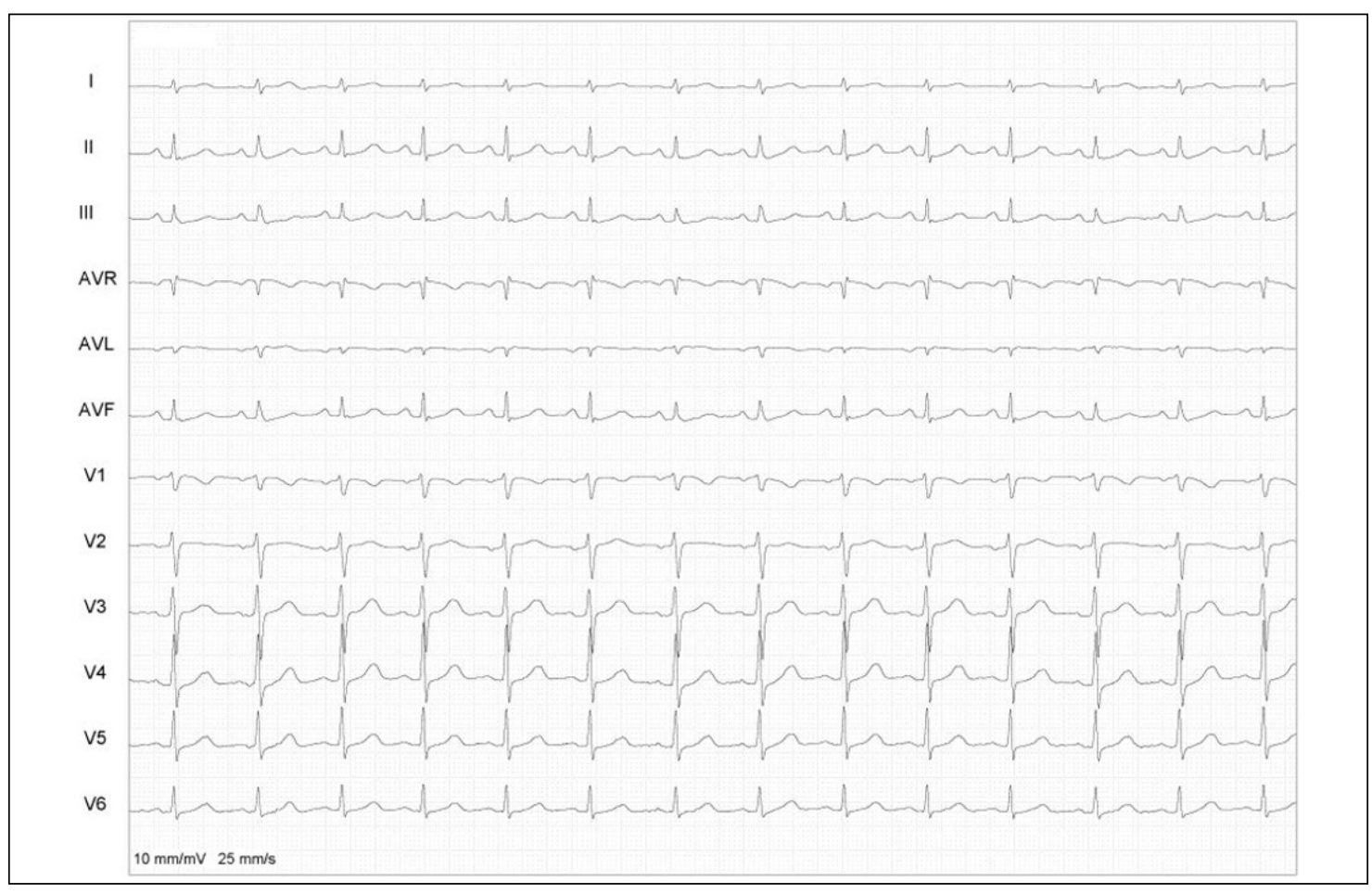

Figure 7. Final post-intervention electrocardiogram. 


\section{DISCUSSION}

The presence of two concomitant anomalous pathways in WPW Syndrome is an uncommon situation. Two anomalous pathways participating in the same AVT with intermittent retrograde ventriculoatrial (VA) conduction varying between the two pathways without interrupting the AVT is a rare and challenging condition at the time of diagnosis during the electrophysiological study.Intermittent change in the direction of AV T retrograde activation without its interruption can confuse the diagnosis, requiring experience by the electrophysiologist team, confirmation of non-displacement of the coronary sinus decapolar electrode and electrophysiological diagnostic maneuvers, as this situation is rare and may confuse the correct diagnosis or lead to a prolongation of the procedure time, given the detail of the AVT retrograde pathway change in the same tachycardia.

Several risk factors for sudden death have been considered in WPW Syndrome. Among them, the presence of an effective refractory period $(\mathrm{ERP})<250 \mathrm{~ms}(210 \mathrm{~ms}$ in the present case) and also multiple accessory pathways, defined by the presence of more than one electrical conduction pathway separated by a distance of $2 \mathrm{~cm}$. The presence of multiple accessory pathways (it is described in structural heart diseases (SHD), such as Ebstein's anomaly and cardiomyopathies, however we can find it with rare frequency in patients with structurally normal hearts ${ }^{8}$.

A retrospective study with 251 patients diagnosed with WPW Syndrome demonstrated that 31 (12.4\%) had multiple accessory pathways, with 18 (7.2\%) having a history of documented ventricular fibrillation. When compared with patients with a single accessory pathway, the study mentioned above showed that these patients had a lower mean age and also an increased risk $(51.6 \times 29.1 \% \mathrm{p}=0.004)$ of having an episode of atrial fibrillation, a condition that increases the risk of sudden death from ventricular fibrillation regardless of RR interval during atrial fibrillation.

The reason for the increased risk of atrial fibrillation and ventricular fibrillation in patients with multiple accessory pathways is not clear, however the presence of such a condition implies recurrence of symptoms, as well as an increased risk of sudden death, and these patients should be referred for early ablation ${ }^{5}$.

\section{CONCLUSION}

This case illustrates that some anomalous pathway ablations can be challenging and laborious, even with the immense expertise accumulated in recent decades in relation to catheter ablation,eventually with anatomical difficulties, presence of other pathways, difficulty in mapping and diagnostic challenges, as in the case reported, which, as mentioned above, consists of a rare form of AVT seen in electrophysiology laboratories. Therefore, the intention here was to draw attention to this condition, which, despite being rare, can exist.

\section{AUTHOR'S CONTRIBUTION}

Conceptualization: Marengo TS, Porto FM; Methodology: Marengo TS, Martins V, Porto FM, Barbosa GV; Writing - Original Draft: Marengo TS; Writing - Review and Editing: Barbosa GV; Supervision: Porto FM, Cury Filho H, Lucena Neto AB, Lima JMN; Critical revision: Dietrich CO.

\section{DATA AVAILABILITY STATEMENT}

The datasets generated during and/or analyzed during the current study are available from the corresponding author on reasonable request. 


\section{FUNDING}

This study was not supported by any funding.

\section{ACKNOWLEDGMENTS}

Not applicable.

\section{REFERENCES}

1. Castellanos A, Agha AS, Befeler B, Myerburg RJ. Double accessory pathways in Wolff-Parkinson-White syndrome. Circulation. 1975;51(6):1020-5. https://doi.org/10.1161/01.cir.51.6.1020

2. James K, Koplan BA. Wolff-Parkinson-White Syndrome and accessory pathways. Circulation. 2010;122(15):e480-3. https://doi. org/10.1161/CIRCULATIONAHA.109.929372

3. Moorman A, Webb S, Brown NA, Lamers W, Anderson RH. Development of the heart: (1) formation of the cardiac chambers and arterial trunks. Heart. 2003;89(7):806-14. https://doi.org/10.1136/heart.89.7.806

4. Mirzoyev S, McLeod CJ, Asirvatham SJ. Embryology of the conduction system for the electrophysiologist. Indian Pacing Electrophysiol J. 2010;10(8):329-38.

5. Colavita PG, Packer DL, PressleyJC, Ellenbogen KA, O'Callaghan WG, Gilbert MR, et al. Frequency, diagnosis and clinical characteristics of patients with multiple accessory atrioventricular pathways. Am J Cardiol. 1987;59(6):601-6. https://doi.org/10.1016/00029149(87)91177-5

6. Zachariah JP, Walsh EP, Triedman JK, Berul Cl, Cecchin F, Alexander ME, et al. Multiple accessory pathways in the young: the impact of structural heart disease. Am Heart J. 2013;165(1):87-92. https://doi.org/10.1016/j.ahj.2012.10.025

7. Holman WL, Kay GN, Plumb VJ, Epstein AE. Operative results after unsuccessful radiofrequency ablation for Wolff-Parkinson-White syndrome. Am J Cardiol. 1992;70(18):1490-1. https://doi.org/10.1016/0002-9149(92)90306-j

8. Teo WS, Klein GJ, Guiraudon GM, Yee R, Leitch JW, McLellan D, et al. Multiple accessory pathways in the Wolff-Parkinson-White syndrome as a risk factor for ventricular fibrillation. Am J Cardiol. 1991;67(9):889-91. https://doi.org/10.1016/0002-9149(91)90626-V 